\title{
A QUESTÃO DA CULTURA E DA SUBJETIVIDADE: REVISÃO DE UM ESTUDO IMPLICADO COM POLÍTICAS AFIRMATIVAS NA EDUCAÇÃO*
}

\author{
Marly Silveira, \\ da Universidade de Brasília.
}

\begin{abstract}
REsUMO: Nos marcos da Constituição Cidadã de 1988 e ordenamentos jurídicos, políticos e socioeconômicos decorrentes, reverberam no campo da educação, repercutindo nas diretrizes nacionais, significativas demandas relativas às condições materiais e imateriais da plena cidadania. Traduzem-se nas intervenções conhecidas como políticas e ações afirmativas, de reconhecimento e valorização de identidades e culturas, e de promoção da igualdade. Nessa temática, destacamos como base do processo, as políticas curriculares de formação dos professores (as) e a concepção e construção de materiais pedagógicos. No intuito de participar dessa discussão, apresentamos a revisão de um estudo que enfoca aspectos das relações entre a questão da cultura e da subjetividade. Entende-se a compreensão dessas relações como pilar da discussão da finalidade e das ações da escola.

Palavras chave: Políticas afirmativas. Formação cultural. Cultura. Subjetividade.
\end{abstract}

INTRODUÇÃO

Observa-se que as políticas públicas para a educação em nosso país - embora distantes de responder às necessidades do desenvolvimento social em curso e aos desejos da maioria de sua juventude - apontam a institucionalização de demandas muito caras a grandes parcelas da população que, historicamente, estiveram à margem da mobilidade em direção a uma vida digna; por exemplo, a incorporação de temas de estudo como história

\footnotetext{
* Artigo recebido em 4/5/2012 e aprovado em 14/8/2012.
} 
e culturas africanas, afro-brasileiras e indígenas aos currículos escolares, e a preparação dos docentes para ensiná-las, uma vez que foram definidos como conteúdos curriculares obrigatórios no início da década. Essa tarefa não tem sido simples, porque exige, além de vigorosos investimentos financeiros, reflexão em profundidade, mobilização e produção de conhecimentos vinculados à análise de problemas e alternativas sociais contemporâneos.

Para fortalecer as discussões e propostas de organização de conteúdos, materiais e práticas de ensino-aprendizagem, formação e gestão em perspectivas como essas, é preciso elaborar as experiências e conhecimentos, atualizar os significados dos princípios norteadores da formação que humaniza. Pensar com os princípios, conceitos ou categorias aqui propostos revela armadilhas e dificuldades, mas também possibilidades de potencializar forças, porque fundamentam e defendem uma visão de mundo possível, resguardando o valor da apropriação de culturas que "nos tornam humanos, um por um", nas palavras de Geertz (apud PINO, 2005, p. 86).

Formas de intercâmbio cultural instituídas - como a obrigatoriedade de introdução da língua brasileira de sinais (instrumento de inclusão nos ambientes escolares) ou as ofertas de formação, na universidade, para educadores camponeses, quilombolas e indígenas - ampliam possibilidades de articulação entre diferenças. Ao serem colocados em prática, de fato, os exemplos anteriores, ao lado de outros projetos que reconhecem e afirmam diversidades, contribuem para transformar as atuais relações escolares, no sentido de desfazer a rede de relações perversas que distorcem o sentido do estar na escola produzindo, no dizer do educador Lino de Macedo, fracassos e fracassados escolares (LINO DE MACEDO apud KUPFER, 2001, p. 128). Segundo a autora, "precisamos de uma teoria que seja capaz de refletir e criar instrumentos para operar com um sujeito em sua articulação com o campo social escolar, uma teoria que supere a dicotomia indivíduo sociedade" (p. 128).

Nesse sentido, retoma-se este estudo cuja temática envolve conceitos estruturantes de aspectos da produção das diferenças e, consequentemente, as desigualdades no campo da educação. Resulta do esforço ao se buscar compreender a relação entre as concepções de cultura e subjetividade, a partir de leituras anteriores sobre políticas de educação, que apontavam a incorporação de princípios como igualdade e diversidade humanas e pluralidade cultural. Existe a pertinência de atualizá-lo em função de dois objetivos inquietantes: a) sustentar a concepção de projetos de formação e construção de materiais pedagógicos que efetivamente sirvam para enfrentar e superar concepções, práticas e representações de cunho excludente, 
presentes nas relações cotidianas das escolas; b) e, em perspectiva crítica, elucidar ambivalentes experiências de pertencimento e deslocamento, vivenciadas por estudantes e professores, especialmente os negros, em suas trajetórias escolares.

Especifica-se a experiência negra brasileira por dois motivos: pelas profundas marcas do racismo institucional, a exemplo da não representatividade dos negros nos espaços de prestígio, nas organizações políticas e no mundo do trabalho, estruturando as desigualdades; e por vivências pessoais de discriminação e violência racial, relatadas por estudantes e professores(as). Relatos em pesquisas - como as de Bento (1992), Cavalleiro (2003), Oliveira (1992), Weller (2011) e outros - atestam a vigência dessa prática em espaços destinados à educação das crianças e jovens e à socialização e profissionalização do(a) professor(a). West (1994) diz que "o racismo produziu identidades destroçadas onipresentes na América negra", produto de um pensamento liberal que não concebe cultura como o universo dos significados e valores, e adota uma maneira restrita e relativista de discutir as relações raciais e a educação, deixando de lado as realidades existenciais e psicológicas dos negros (WEST, 1994, p. 29).

Observando o percurso cotidiano do desenvolvimento de uma criança (processo que se denomina como marcas do humano) no interior das relações familiares, nos dias de hoje e na sociedade brasileira, Pino se apoia na concepção de Geertz, quando este examina o impacto do conceito de cultura sobre o conceito de homem. Para o antropólogo, a cultura é "um conjunto de mecanismos simbólicos para controle do comportamento, ou sistemas de significados criados historicamente em termos dos quais damos forma, ordem, objetivo e direção às nossas vidas". Dessa forma, "a cultura fornece o vínculo entre o que os homens são intrinsecamente capazes de se tornar e o que eles realmente se tornam, um por um" (PINO, 2005, p. 86).

Entretanto, essa que seria a condição da subjetividade humana é tirada desse lugar e particularizada quando a qualidade humana é negada, inferiorizada em uma forma de ruptura da racionalidade que caracteriza sua constituição nos processos da cultura. Nesse sentido, uma racionalidade particularizada torna possível uma subjetividade negra que, desqualificada em sua humanidade, tornou-se uma subjetividade destroçada, fragmentada nas cicatrizes da discriminação que a inferioriza e exclui do humano. De outro lado, o branco, que não é capaz de ver o outro como humano igual, também é destroçado, podendo sofrer de "uma inflação valorativa de si mesmo" (BENTO, 1992). Em consequência, a lógica desse pensamento admite a exclusão. Assim funciona a subjetividade de qualquer preconceituoso que restringe e exclui 
o outro da categoria humana. O humano é universal e a particularidade é construída nas condições históricas e se explicita na discussão dos sentidos da cultura. A singularidade ao nível individual é a forma como esse sujeito equaciona sua humanidade na particularidade histórica da qual é parte atuante.

Nessa perspectiva, a educação comprometida com a valorização das culturas africanas, afro-brasileiras e indígenas, fundantes da pluralidade cultural brasileira, precisa levar em conta as contradições de sua inerência ao projeto, pensamento e políticas que constituem seu atual estágio de desenvolvimento social. Segundo observações críticas, os processos recentes da chamada globalização da economia e correlações socioculturais, ao mesmo tempo que sedimentam a produção da diversidade, tendem a transformar tudo que é diverso no mesmo, tendendo à homogeneização. Por isso, tentamos compreender as imbricações entre formação cultural, educação e construção de subjetividades, com base em algumas leituras que certamente trarão pistas para futuros destaques da função formadora entre os objetivos determinantes da valorização pela transmissão e apropriação das formas culturais, que dão vida à educação no Brasil contemporâneo.

A reflexão construída a seguir começa reunindo ideias de Gramsci sobre a organização da cultura como um elemento intrínseco à racionalização da produção e do trabalho, cuja concepção abarca a constituição e a subjetivação dessa racionalidade no processo social. Segue reconstruindo o entendimento de Crochik sobre subjetividade, como fruto de um projeto histórico implícito no nosso desenvolvimento civilizatório, para além do fundamento nas atuais circunstâncias sociais. O terceiro movimento traz para o texto a discussão de Resende sobre o tema da subjetividade fundada em alguns aspectos do pensamento marxista.

\section{A QUESTÃO DA CULTURA NA CONCEPÇÃO DE GRAMSCI}

Na concepção de Gramsci, o sujeito desenvolve um nexo psicofísico nas condições históricas. Essa ideia pode ajudar a compreender tanto a formação do sujeito individual, particular, como a formação das massas necessárias à produção da cultura instrumentalizada para a manutenção da moderna sociedade de consumo.

Encontra-se uma forte vinculação, no pensamento de Gramsci, entre conhecimento histórico, práxis política, luta cultural e formação humana, o que contribui para a compreensão de uma dimensão menos abrangente e interna aos termos que ele analisa, os quais dizem respeito mais diretamente à noção de luta cultural por ele construída (GRAMSCI apud VIEIRA, 1999). 
Isso quer dizer que a reflexão de Gramsci sobre a formação do homem em sociedade é inseparável de sua teoria política. Nessa indissociação, entre um projeto político e a formação dos homens que o realizam, o autor afirma que a questão da formação do indivíduo ocupa função estratégica na realização do projeto de uma classe na perspectiva de se fazer hegemônica, como tarefas de lideranças, como responsabilidades dos mais velhos perante os mais jovens, na perspectiva de criar formas mais avançadas de civilidade (VIEIRA, 1999, p. 51).

Na direção apontada por essa indissociação, pode-se pensar uma teoria de formação humana que evite reduzir a compreensão do processo formativo ao desenvolvimento intelectual, de forma unilateral, como também a concepção determinista da formação da personalidade, que reduz o homem a produto do meio. Na concepção gramsciana, a formação humana é parte de um complexo e contraditório processo de luta cultural.

As posições de Gramsci são marcadas pela crítica das interpretações naturalistas e positivistas do homem e da história, tais como as da antropologia lombrosiana, do evolucionismo histórico spenceriano, ou de algumas correntes materialistas, definindo o homem como espírito, isso é, criação histórica e cultural (GRAMSCl apud VIEIRA, 1999, p. 57). Ele afirma o homem como sujeito da história e, no plano da intervenção política, prioriza a difusão da cultura humanista e filosófica na classe operária através das organizações, visando sua autonomia intelectual. Para ele, a organização e a difusão da cultura adquirem centralidade no interior da luta socialista da qual se ocupa, cujo processo de afirmação dependeria da criação de bases para uma transformação social que, por sua vez, engendrasse uma cultura autônoma, própria da ascensão da classe operária, determinando novos modos de ser que resultassem em outra forma de consciência.

Em uma das revisões que faz no processo de elaboração de seu conceito de cultura (para ele, central na luta política), Gramsci o amplia para além da ideia de universal a ser distribuído igualmente a todas as classes e passa a afirmar que todos são cultos. Nessa perspectiva histórica inclusiva, que deixava de considerar os setores populares como receptores de uma cultura produzida por um outro grupo, dependentes de políticas de distribuição, todos os homens podem ser críticos e produtores de conhecimento. A partir dessa ideia que considera a capacidade de todos para pensar - embora nem todos tenham as mesmas condições de elaboração e exposição de seus conceitos -, desenvolve-se uma valorização do conhecimento e da criatividade dos homens e mulheres que não receberam a chamada formação cultural tradicional. 
O núcleo dessa ampliação conceitual diz que todos os homens são filósofos e intelectuais, ou seja, intelectualmente desenvolvidos. Entretanto, não se deve entender a defesa de uma cultura popular abstrata em detrimento da cultura sistematizada. Essa noção sinalizaria para uma condição de potencial igualdade diante do conhecimento, não se esgotando na ideia de uma natureza ou de uma essência humana racional, proposta nas filosofias de Platão a Descartes. O entendimento correto seria que todos são cultos porque participam da vida, confrontam-se com a natureza e a sociedade, defrontamse com problemas reais e produzem soluções práticas. Os conceitos de cultura e de homem culto precisariam ser revistos, particularmente a partir das considerações das dimensões utilitárias e produtivas da vida, próprias do mundo do trabalho, que historicamente foram excluídas da concepção de cultura (VIEIRA, 1999, p. 59).

Essas postulações ampliaram-se em época de movimentação cultural e social, em face de tendências surgidas com as novas condições de desenvolvimento. Uma noção cultural que não considera a experiência passada como tradição, mas como estímulo à criação, incita a possibilidade histórica de uma classe ou segmentos sociais, antes em desvantagens, capacitarem-se para as funções de direção da sociedade, com autonomia e originalidade. Para essas finalidades, a concepção socialista gramsciana supõe uma ação político-cultural que inclui todas as dimensões de um projeto de sociedade, capaz de reformá-la, de transformar o modo de vida e as mentalidades (GRAMSCl apud VIEIRA, 1999, p. 60).

A elaboração e refinamentos desse conceito de cultura se fazem refletindo-se sobre a inclusão da questão do trabalho, ao mesmo tempo da disjunção, no interior da teoria política, dos processos técnicos e das funções produtivas em diferentes estágios da industrialização, em face da apropriação privada da riqueza sob o capitalismo. O termo cultura passa a significar um modo de viver que se produz e reproduz por meio de um projeto de formação. A questão que se abre nessa análise da cultura teria íntima relação com a estrutura social: a cultura, materializada em uma rede de associações, compreendida estruturalmente, tendo-se presente que homens, grupos e classes sociais movimentam-se nessas estruturas, lutando pelos seus projetos, pelas suas ambições, determinando uma dinâmica social permanente e imprevisível nos resultados (VIEIRA, 1999, p. 62).

Explicita-se, assim, o que nessa leitura consideramos de interesse central, ou seja, a questão da cultura como luta social ou, na expressão original, luta cultural. A relação cultural não se reduziria a um embate entre dominantes e dominados, ou entre cultura erudita e cultura popular, 
pois as relações entre os segmentos e a sociedade incluem liberdade, constrangimento, projetos, práticas e determinação, em cujo âmbito se desenvolveria essa luta. Processando-se na interação de muitos ambientes, como família, região, língua, classe social, religião, escola, trabalho, a cultura em diferentes épocas resultaria do embate e da intervenção das concepções, experiências e práticas que perpassam essas ambiências culturais, sendo que as posições diferenciadas na estrutura econômica vão determinar diferentes relacionamentos.

Pode-se entender de sua discussão que a organização socioeconômica constrói, historicamente, um conjunto de exigências que, impondo transformações na atividade humana, vai produzi-las tanto nos sujeitos que as praticam, como nas instituições sociais. Na perspectiva histórica dessa concepção, o pensador observou que a vida na indústria exigia uma experiência geral, um processo de adaptação psicofísica para determinadas condições de trabalho, envolvendo suas formas de nutrição, de habitação e costumes, como maneiras de viver que deveriam ser adquiridas. Esse processo de adaptação faria parte da racionalização da produção e do trabalho, criando condições básicas das transformações em desenvolvimento em dada sociedade.

Em sua observação, Gramsci exemplifica que, nos Estados Unidos da América, "a racionalização determinou a necessidade de elaborar um novo tipo humano" (GRAMSCl, 1978, p. 316), integrado à organização produtiva. Tal integração adaptativa consiste na criação e na modificação de comportamentos como gestos, expressões, percepções e automatismos, justificados internamente por uma nova maneira de pensar. As transformações nas instâncias da vida social exercem pressões, combinando habitualmente a força com a persuasão, no redimensionamento dos modos de vida individual e coletivo, sob a lógica que pensa e organiza os meios de produção.

A lógica dessa racionalização, que tem como substrato a ideologia, se inscreve no nexo psicofísico. As pessoas desenvolvem uma atividade mental relacionada intrinsecamente à sua ação concreta, o que equivale a dizer que seus gestos e expressões são mediados por representações com as quais elas significam suas realizações. O nexo psicofísico, pela força da função de consenso das ideologias, realiza o convencimento individual e grupal sobre a liberdade e necessidade de seus atos.

\section{OS DESAFIOS ATUAIS DO ESTUDO DA SUBJETIVIDADE NA PSICOLOGIA}

Os desafios se referem à visão de Crochik, em seu pressuposto de que para além do fundamento nas circunstâncias sociais atuais, a subjetividade 
é fruto também de um projeto histórico implícito no desenvolvimento civilizatório. A partir desse entendimento, Crochik (1998) propõe uma dupla perspectiva para problematizar seu estudo: a noção histórica de indivíduo e a possibilidade atual de realização desse projeto. Em uma linha crítica, discute os desafios atuais do estudo da subjetividade na psicologia, trazendo elementos que aqui são considerados relevantes. Contribuem para construir um percurso na discussão sobre as diferenças e desigualdades, e a possibilidade de construção de relações de igualdade no terreno da formação humana, especialmente com a contribuição da educação. Espera-se que esse percurso nos apoie para elucidar o histórico de uma subjetividade negra, constituída na formação dos sujeitos sociais, os quais guardam, na realidade social brasileira, a memória significativa da experiência de pertencimento à história dos homens e mulheres de origem negro-africana no Brasil.

Na argumentação do autor, o projeto é determinado pelas condições concretas de vida e, ao mesmo tempo, aponta para a superação dessa determinação. Também a cultura prevê a possibilidade de um indivíduo que se assenhore dela, isso é, um indivíduo autônomo, como decorrência necessária do projeto cultural. Kant (apud CROCHIK, 1998, p. 70), em sua análise do projeto histórico da cultura ocidental, considera a razão como um dos seus produtos principais e assinala que sua realização só é possível pelo livre uso individual da cultura, ou seja, pela autonomia individual.

Dessa forma, a cultura como instrumento para a individuação configura-se em um projeto coletivo de formação, destinado à diferenciação do indivíduo em relação ao seu meio. Suas funções seriam: defender os homens das ameaças da natureza, inclusive da sua própria e do outro; e estabelecer regras para a relação entre os homens, ou seja, desenvolver a autonomia humana para o controle da natureza e das regras sociais, assim como para o autocontrole. A formação cultural, em decorrência, tem a função de socializar para a diferenciação ou individuação, o que, segundo Adorno, se dá pela incorporação da cultura, pois a formação não é outra coisa que a cultura pelo lado de sua apropriação subjetiva. Ou seja, os indivíduos só desenvolvem a sua subjetividade, tornam-se indivíduos, na cultura e através dela; eles não existem a priori, são produtos da cultura, e mesmo o passado só pode ser rememorado pelos símbolos que vão sendo adquiridos (ADORNO apud CROCHIK, 1998, p. 71).

Nesse sentido, a subjetividade representaria uma face interna de um mundo externo, elaborada pela apropriação da cultura. Através dessa formação, o indivíduo - que ao nascer se encontrava em confusão com seu meio social e natural - pode expressar seus anseios particulares e criticar 
a própria formação. Isso significa que a mediação da cultura permite ao indivíduo entender o processo de adaptação que institui sua subjetividade, e pensar a própria cultura. Nessa mesma direção, os processos psicológicos estão intimamente integrados aos processos da sociedade e da cultura, embora não se reduzam a eles. Apesar da sua adaptação continuada à cultura, o indivíduo, em processo de diferenciação, dela pode se distinguir em contínua autorreflexão.

Por outro lado, o descolamento entre a cultura e a individualidade geraria uma duplicidade, ou como diz Crochik, uma certa esquizofrenia tanto no projeto histórico da subjetividade, como em sua expressão na formação da personalidade, ao nível da qual constituem-se as características pessoais, através do desenvolvimento de comportamentos racionais, necessários à vida cotidiana. Essa adaptação que forma o indivíduo para espelhar a cultura, produz, ao mesmo tempo, traços de caráter que se formam como resistência à própria adaptação. Pelo lado do projeto de subjetividade, a adaptação é negada pelo reconhecimento das possibilidades de modificação desse mesmo projeto cultural, que se apresenta como crítica ao papel da ideologia como mantenedora da realidade existente. As contradições aparecem com a percepção dos buracos existentes entre o que é dito pela ideologia e o que é na realidade. Nessa dialética da adaptação, entretanto, o indivíduo ameaçado entra em sofrimento que a ideologia tenta negar, procurando formas de harmonizar sua existência com a realidade da cultura que o nega, encobrindo o mal-estar.

Evidencia-se nessa análise que a psicologia cumpre atribuições ideológicas em relação à subjetividade como seu objeto de estudo. Quando interpreta e encaminha soluções para o sofrimento ao nível do próprio indivíduo, oblitera o reconhecimento de sua origem nos conflitos sociais. Essa prática pode se concretizar por duas formas: ou o indivíduo é considerado inadequado, por ser fonte de seu próprio sofrimento e, por isso, deve ser encaminhado a tratamento, como as psicoterapias; ou deve ser instado a conviver com um sofrimento considerado inerente à sua própria existência. Atribuições similares se verificam nas influências recebidas de algumas correntes psicológicas no pensamento pedagógico. Essa denúncia torna flagrante uma contradição entre a psicologia e seu principal objeto, 0 indivíduo em sua dimensão subjetiva, quando ela, ao invés de esclarecê-lo sobre a verdade de seu sofrimento, colabora com sua alienação.

Uma psicologia seria produtora de alienação ao considerar que os problemas do indivíduo têm uma verdade própria, independente da cultura. Em decorrência, o estudo da subjetividade só pode ser realizado por uma 
psicologia cujo caráter ideológico seja assumido e ela se torne crítica da psicologia. Uma vez percebido seu objeto em múltiplas relações, a psicologia crítica esclarece e indica a necessidade de transformação das condições sociais que mutilam a existência do sujeito. Logo, essa perspectiva prevê que a psicologia se volte para o questionamento dessas condições e - ao invés de colaborar com a manutenção do que existe só na aparência - busque entender sua produção. Além disso, devido à complexidade desse objeto, que remete ao mesmo tempo à universalidade e à particularidade, indica-se ser indispensável o recurso a uma confluência de estudos nas áreas da ciência.

\section{SOBRE A CONSTRUÇÃO DE UMA SUBJETIVIDADE QUE RESULTA DESTROÇADA}

Resende (1992) revela - em sua discussão sobre o tema da subjetividade, problematizando-a com aportes recolhidos de diversos momentos do pensamento marxista - a possibilidade de esse debate ganhar em concreticidade, se orientado nesse pensamento. Afirma que suas categorias de análise permitem elucidar a construção de uma subjetividade que resultou destroçada, reificada, e que a vida individual, espiritual e subjetiva será convertida em uma abstração quando for compreendida, deixando de fora seu caráter de manifestação real do conjunto social. Quando despregadas da objetividade das práticas sociais, as expressões da vida subjetiva nada mais seriam que uma "nebulosidade abstrata, em que reina o irracional, carente de um objeto real" (RESENDE, 1992, p. 10).

Nessa discussão, há uma vinculação dialética nas acepções dos conceitos envolvidos no debate sobre subjetividade e objetividade na construção do indivíduo e da sociedade. Fora dessa vinculação, a autonomização da subjetividade frente à objetividade do indivíduo em relação à sociedade está fundada no suposto de uma relação de externalidade e exclusão entre esses dois termos, o que permitirá, da mesma forma, autonomizar também a sociedade, a objetividade frente ao indivíduo e à subjetividade, como em um jogo de luzes e sombras. Entre a atividade luminosa e a passividade obscura, os termos se chocariam: ora a sociedade estaria do lado da luz, da atividade, e o indivíduo constituído como mero reflexo escurecido e passivo dessa luminosidade; ora o indivíduo passaria para o lado apolíneo, portanto, uma independência luminosa frente à passividade obscura da sociedade. A autonomização desses elementos - que produz a abstração e fetichização de ambos - implica sempre a impossibilidade de resolução efetiva de sua apreensão. Por mais contraditória que pareça, a negação da vida subjetiva enquanto uma realidade concreta termina por 
derivar, para além de uma subjetividade pura, uma objetividade abstrata (RESENDE, 1992, p. 10).

Nessa perspectiva, pensar os problemas sociais sem a concorrência de sua dimensão subjetiva equivale a um sociologismo, da mesma forma que se a análise prossegue desconectada de sua objetividade cai no psicologismo. Isso resulta de estudos que menosprezam o valor de categorias como o indivíduo, a subjetividade, o psiquismo, na análise objetiva da sociedade. Em seu Prefácio da crítica da economia política, Marx coloca o fio condutor:

Na produção social da própria vida, os homens contraem relações determinadas, necessárias e independentes de sua vontade, relações de produção estas que correspondem a uma etapa determinada de desenvolvimento de suas forças produtivas materiais. A totalidade destas relações forma a estrutura econômica da sociedade, a base real sobre a qual se levanta uma superestrutura jurídica e política, e à qual correspondem formas sociais determinadas de consciência. O modo de produção da vida material condiciona o processo em geral da vida social, política e espiritual. Não é a consciência dos homens que determina o seu ser, mas ao contrário, é o seu ser social que determina sua consciência. (MARX apud RESENDE, 1992, p. 10-11)

Parece claro que a unidade entre essas duas realidades esteja distante de uma concepção metafísica e dualista da vida espiritual e da realidade. Fica então difícil concordar com o suposto de um socialismo positivista que trace uma linha divisória rígida entre a vida subjetiva e seu objeto social. O estudo de Resende faz a crítica das análises - filiadas, de um lado, à metafísica e, de outro, ao positivismo - que, negando o espiritual e o subjetivo no âmbito do pensamento, operam estabelecendo: a primeira, uma coincidência acientífica entre representação e conceito; e a segunda, uma ruptura antidialética entre o sujeito e o objeto. Essa coincidência significaria abdicar do conceito que é conversão e elaboração da representação, e desconsiderar a totalidade concreta como totalidade de pensamentos. A totalidade como um concreto de pensamento é, de fato, um produto do pensar, do conceber, e não é, de modo algum, o produto do conceito que pensa separado e acima da intuição e representação, ou que se engendra a si mesmo (KORSH apud RESENDE, 1992, p. 11-13).

Esse trabalho de elaboração da representação em conceito, realizado pelo pensamento, é que possibilita atravessar a aparência, pois o concretoimediato não diz a verdade do objeto de reflexão, mas cria uma ilusão que a encobre. "Essa ilusão posta na aparência poderá ser superada pelo movimento do pensamento que apreende as mediações constitutivas do 
objeto e descobre, dessa forma, o cerne racional dentro do invólucro místico" (RESENDE, 1992, p. 14).

Algumas formas mistificadas de consciência seriam produto e pressuposto do modo capitalista de produção e reprodução, cuja crítica desenvolve-se através de uma análise da realidade social que seja capaz de reverter essas representações fetichizadas da consciência. Esta, embora determinada pelos processos de produção social, é tomada como parte positiva da atividade do homem em sua apropriação da realidade. Em decorrência de sua atividade concreta, cada vez mais aspectos e propriedades se constituem nele e a consciência se apropria de uma imagem cada vez mais rica e múltipla da sociedade e de si. Nesse movimento, sua evolução humana se realiza em sua consciência cotidiana empírica, em sua sensibilidade, em sua subjetividade (RESENDE, 1992, p.15). A subjetividade, concebida como manifestação real da vida social, é incorporada pelos sujeitos que são constituição da cultura. Nela inseridos desde suas origens, dela se apropriam pelos processos de mediação, o que indica que devemos neles procurar marcas integradoras da relação indivíduo e sociedade.

\section{CONSIDERAÇÕES COM VISTAS A NOVAS ATUALIZAÇÕES}

A tarefa de formar professores qualificados para enfrentar os desafiadores temas e questões contemporâneos exige traduzir para uma linguagem pedagógica contribuições teóricas de diversos campos do conhecimento. $\mathrm{O}$ trabalho solitário de estudar constantemente exige alto empreendimento de tempo, energia e dedicação e traz, em contrapartida, alento espiritual; no caso deste estudo, embora preliminar e muito limitado em abrangência, deixa entrever instigantes pistas para caminhar em diferentes, porém convergentes, direções.

A fertilidade que pode decorrer das ideias de Gramsci, para introduzir reflexões a respeito das concepções sobre a construção de subjetividades circulantes no campo da educação, é um exemplo de descoberta alentadora. Oferece suporte filosófico e político para um olhar diferenciado em direção à concreticidade das relações cotidianas, na observação das vivências possíveis nas maneiras de viver em curso nos tempos presentes. A imbricação entre essas vivências e as sutilezas e contradições das relações constitutivas da formação cultural, certamente, serão trilhas para o esclarecimento de processos referidos a conceitos como subjetividade e identidade negras.

Os aportes da psicologia social de Adorno, Horkheimer e outros críticos trazidos por Crochik representam, também, fortes possibilidades de diálogo com abordagens metodológicas e estratégias de pesquisa e 
documentação, desenvolvidas nos estudos sobre cultura escolar e formação de educadores, como os relatos biográficos, as histórias de vida, as entrevistas narrativas, dentre outros. Até mesmo a memória, diz Adorno, para ser mobilizada, reapropriada, e o passado para ser rememorado o serão pelos símbolos que vão sendo adquiridos, ou seja, pela produção de linguagem e pelo conhecimento construído.

$\mathrm{Na}$ abertura a próximas direções, o estudo assinala convergência de objetivos com o estudo de Assunção (2007) sobre concepções de subjetividade que permeiam a área educacional, originárias dos campos da psicologia social, da psicanálise e da psicologia histórico-cultural. Por último, neste esboço de ensaio introdutório, um alento em relação ao segundo objetivo: pensar o sofrimento decorrente da ambivalência de um sentimento duplamente obscuro. De um lado a expectativa de acolhimento e pertença a círculos de relações, a exemplo de grupos de adolescentes na escola; de outro, a sensação de deslocamento, de ocupar um lugar inapropriado ou impróprio para si. Com base na crítica à psicologia e na análise da formação em que a subjetividade resulta fragmentada, explicita-se o vetor político do sofrimento pessoal e erige-se um ponto de partida para outras leituras e considerações.

THE QUESTION OF CULTURE AND SUBJECTIVITY: A REVIEW OF A STUDY ON AFFIRMATIVE EDUCATIONAL POLICIES

AвSTRACT: In the aftermath of the 1988 'Citizen' Constitution and the ensuing legal, political and socio-economic regulations, weighty demands in terms of material and immaterial conditions for total citizenship echoed in the field of education with repercussions for the national guidelines. These demands were translated into interventions known as affirmative policies and actions of acknowledgment and valorization of identities and cultures, as well as the promotion of equality. As a basis for this process, we highlight curriculum policies, teacher formation and the conception and designing of teaching material. As a way of contributing to this discussion, we present a review of a study which focuses on certain aspects of the relationship between culture and subjectivity. This relationship is understood as the basis for the debate on the purpose and actions of the school.

KEYWORDS: Affirmative policies. Cultural formation. Culture. Subjectivity.

\section{EL TEMA DE LA CULTURA Y DE LA SUBJETIVIDAD: REVISIÓN DE UN ESTUDIO RELACIONADO A POLÍTICAS AFIRMATIVAS EN LA EDUCACIÓN}

Resumen: Dentro de los marcos de la Constitución Ciudadana de 1988 y de los ordenamientos jurídicos, políticos y socio-económicos de ellos derivados, retumban 
en el campo de la educación, repercutiendo en las directrices nacionales, demandas significativas relativas a las condiciones materiales e inmateriales de la plena ciudadanía. Estas se traducen en intervenciones conocidas como políticas y acciones afirmativas, de reconocimiento y valoración de identidades y culturas, y de promoción de la igualdad. En esa temática, destacamos, como base del proceso, las políticas curriculares, de formación de profesores y la concepción y construcción de materiales pedagógicos. Con el deseo de participar de esa discusión, presentaremos la revisión de un estudio que enfoca aspectos de las relaciones entre el tema de la cultura y el de la subjetividad. Se entiende la compreensión de esas relaciones como pilar de la discusión sobre la finalidad y las acciones de la escuela.

Palabras Claves: Políticas afirmativas. Formación cultural. Cultura. Subjetividad.

\section{REFERÊNCIAS}

ASSUNÇÃO, M. M. S. Subjetividade, um conceito entre as fronteiras do discurso científico. In: SILVA, I. O.; VIEIRA, M. L. (Org.). Memória, subjetividade e educação. Belo Horizonte: Argvmentvm; Três Corações: Unincor, 2007.

BENTO, M. A. S. Discriminação racial no trabalho e resistência na voz dos trabalhadores negros. Dissertação de mestrado. São Paulo: PUC, 1992.

CAVALLEIRO, E. Do silêncio do lar ao fracasso escolar: racismo, preconceito e discriminação na educação infantil. 2. ed. São Paulo: Contexto, 2003.

CROCHIK, J. L. Os desafios atuais do estudo da subjetividade na psicologia. Psicologia, USP, São Paulo, v. 9, n. 2, p. 69-85, 1998.

GRAMSCl, A. Americanismo e fordismo. In: Obras escolhidas. Trad. Manuel Cruz. São Paulo: Martins Fontes, 1978. p. 311-337.

KUPFER, M. C. Educação para o futuro: psicanálise e educação. 2. ed. São Paulo: Escuta, 2001.

OLIVEIRA, R. Relações raciais na escola: uma experiência de intervenção. Dissertação de mestrado. São Paulo: PUC, 1992.

PINO, A. As marcas do humano: às origens da constituição cultural da criança na perspectiva de Lev. S. Vigotski. São Paulo: Cortez, 2005.

RESENDE, A. C. A. Fetichismo e subjetividade. Tese de doutorado. São Paulo: PUC, 1992. VIEIRA, C. E. Cultura e formação humana no pensamento de Antônio Gramsci. Educação e Pesquisa, São Paulo, v. 25, n. 1, p. 51-66, jan./jun. 1999.

WELLER, W. J. Minha voz é tudo que eu tenho: manifestações juvenis em Berlim e São Paulo. Belo Horizonte: Editora UFMG, 2011.

WEST, C. Questão de raça. São Paulo: Companhia das letras, 1994. 
MARLY SILVEIRA é professora adjunta na Faculdade de Educação, Departamento de Teoria e Fundamentos da Universidade de Brasília; vinculada à Rede de Pesquisa sobre Professores(as) no Centro Oeste REDECENTRO; colaboradora do Centro de Estudos das Relações de Trabalho e Desigualdades - CEERT/SP.

E-mail: silveira.marly@gmail.com 